\title{
Ethanol Fermentation by High-Stress-Tolerance Aquatic Yeasts and Their Mutants
}

\author{
Naoto Urano', Masami Ishida', Yuka Naito', Rintaro Endoํ, Toshinori Takei2, \\ Masachika Takashio², Masahiko Okai ${ }^{*}$
}

${ }^{1}$ Laboratory of Marine Biochemistry, Department of Ocean Sciences, Tokyo University of Marine Science and Technology, Tokyo, Japan

${ }^{2}$ Zensho Laboratories of Food Technology, Zensho Holdings Co. Ltd., Tokyo, Japan

Email: *mokai01@kaiyodai.ac.jp

How to cite this paper: Urano, N., Ishida, M., Naito, Y., Endo, R., Takei, T., Takashio, M. and Okai, M. (2021) Ethanol Fermentation by High-Stress-Tolerance Aquatic Yeasts and Their Mutants. Advances in Microbiology, 11, 616-629.

https://doi.org/10.4236/aim.2021.1111045

Received: October 19, 2021

Accepted: November 8, 2021

Published: November 11, 2021

Copyright (C) 2021 by author(s) and Scientific Research Publishing Inc. This work is licensed under the Creative Commons Attribution International License (CC BY 4.0).

http://creativecommons.org/licenses/by/4.0/

\begin{abstract}
Bioethanol is thought to be a renewable source of energy, because the biomasses used to make ethanol, such as sugar cane and its residual substance, molasses, are resources that can be continuously produced. But the practical use of ethanol to replace fossil fuels or atomic energy has been limited, because the production efficiencies of ethanol in relation to its substrates are not so high. Thus, for industrial production of the bioethanol, yeast fermentation would ideally be carried out in biomasses containing more highly concentrated carbohydrates. However, the environmental stresses in highly concentrated cultures might weaken the yeast's physiological activities. From various kinds of aquatic yeast with stress tolerance, Torulaspora derbrueckii F2-11 and Wicherhamomyces anomalus AN2-64 were selected as candidates for high-sugar-tolerance yeasts as they showed remarkable growth in the YPD + sorbitol $(600 \mathrm{~g} / \mathrm{L})$ medium at $25^{\circ} \mathrm{C}$ for $120 \mathrm{hrs}$. When the amounts and kinds of sugar alcohols in the cells of the two strains were measured in cultures containing $20 \mathrm{~g} / \mathrm{L}$ or $400 \mathrm{~g} / \mathrm{L}$ of $\mathrm{D}$-glucose, maltose, or sucrose, the main two sugar alcohols that accumulated as the sugar concentration increased were glycerol and arabitol. Mutation by ethyl methanesulfonate of the parent strains T. derbrueckii F2-11 and $W$. anomalus AN2-64 induced mutants F2-11M or AN2-64M, which showed higher sugar, heat, and ethanol tolerances than their respective parents. Ethanol productivities and sugar assimilation activities of the mutants were also higher than those of the parents in the $25 \%(\mathrm{v} / \mathrm{v})$ molasses.
\end{abstract}




\section{Keywords}

Ethanol Fermentation, Stress Tolerance, Aquatic Yeast, Mutant, Ethyl

Methanesulfonate (EMS)

\section{Introduction}

Yeasts are eukaryotic microorganisms that have been used for millennia in a wide range of industries including food production and liquor brewing [1]. Recently, bioethanol has been attracting attention as a route to obtaining a low-carbon circular economy; namely, it can substitute for fossil fuels, which cause serious global warming, and atomic energy, which carries enormous safety concerns and is less portable. Bioethanol is thought to be a renewable energy source, because the biomasses used to make it, such as sugar cane and its residual substance, molasses, can be continuously produced [2] [3]. Several review articles about bioethanol production by yeasts have been published [4] [5], but its actual use replacing fossil fuels or atomic energy has been limited, because ethanol production from substrates is not very efficient. For industrial production of bioethanol, yeast fermentation would ideally be carried out in biomasses containing more highly concentrated carbohydrates. However, highly concentrated cultures can produce environmental stresses such as accumulated salts, sugars, or ethanol, which weaken the physiological activities of most yeasts and reduce ethanol productivity [6] [7]. Recently, marine yeasts with stress tolerance against salt water (about $3 \% \mathrm{w} / \mathrm{v} \mathrm{NaCl}$ ) were isolated and applied to the improvement of bioethanol production [8] [9]. We also have been studying various kinds of stress-tolerant yeasts from non-marine aquatic environments: we isolated thermotolerant fermentative yeasts from hot spring drainage [10] [11] [12] and produced bioethanol from highly concentrated saccharified suspensions of water hyacinth [13] [14], paper shredder scrap [15], and seaweed [16] [17] [18]. We also characterized salt-tolerant yeasts [19], and those tolerant to other stressors [20] [21].

In industrial-scale bioethanol production from molasses, the sugar concentration is often more than $40 \%(\mathrm{w} / \mathrm{v})$ [22]; the yeasts are required to have considerable fermentative ability even under such high stress pressures. Bloomberg et al. noted that yeast Saccharomyces cerevisiae accumulated sugar alcohols, mainly glycerol, postulating it as a compatible solute in cells to improve their stress tolerance under various high-stress pressures [23].

In this study, we surveyed our microbial library [21] for fermentative yeast strains known to have higher stress tolerances, and assayed the amounts and kinds of accumulated sugar alcohols serving as compatible solutes in the selected yeasts. For further study, we mutated the yeast strains with ethyl methanesulfonate (EMS) and compared the bioethanol production from molasses of the parents and their mutants. 


\section{Materials and Methods}

\subsection{Aquatic Yeast Strains Used}

Our previous study identified among the 1028 yeast strains isolated from aquatic environments in Japan and bioethanol productions, 31 strains that demonstrated high stress tolerance [21]. Among these, we selected for this study 6 strains or species demonstrating high salt tolerance $(\mathrm{NaCl} 10 \%$ - 15\%): Candida glabrata TC18, Lachancea kluyveri F2-67, Pichia kudriavzevii AN1-13, Saccharomyces cf. cerevisiae/paradoxus H28, Torulaspora derbrueckii F2-11, and Wicherhamomyces anomalus AN2-64.

\subsection{Selection of High Sugar-Tolerant Yeasts from the 6 Strains}

The 6 species strains described above were respectively precultured in $10 \mathrm{~mL}$ of modified YPD liquid medium (D-glucose, $180 \mathrm{~g} / \mathrm{L}$; peptone, $20 \mathrm{~g} / \mathrm{L}$; yeast extract, $10 \mathrm{~g} / \mathrm{L}$ ) at $25^{\circ} \mathrm{C}$ for $48 \mathrm{hrs}$. Each was cultured in $10 \mathrm{~mL}$ of YPD (D-glucose, $20 \mathrm{~g} / \mathrm{L}$; peptone, $20 \mathrm{~g} / \mathrm{L}$; yeast extract, $10 \mathrm{~g} / \mathrm{L})+\operatorname{sorbitol}(600 \mathrm{~g} / \mathrm{L})$ liquid medium at $25^{\circ} \mathrm{C}$ for $120 \mathrm{hrs}$. The growth curve of each culture was detected by BIO-PHOTORECORDER TN-2612 (temperature gradient incubator, Advantec Toyo Kaisha, Ltd., Japan).

\subsection{Assay of Accumulated Sugar Alcohols as Compatible Solutes in the Yeast Cells}

The amount and kinds of accumulated sugar alcohols as compatible solutes in the selected yeasts were measured. Each strain was cultured in $40 \mathrm{ml}$ of yeast nitrogen base (YNB) without amino acids (Becton, Dickinson and Company, USA) + sugar (D-glucose, sucrose, or maltose, $20 \mathrm{~g} / \mathrm{L}$ or $400 \mathrm{~g} / \mathrm{L}$ ) at $25^{\circ} \mathrm{C}$ for 48 hrs. The growing yeast was centrifuged at $3000 \mathrm{rpm}$ for $5 \mathrm{~min}$, and the precipitate was washed with saline. The centrifugation/washing procedure was conducted three times, and the cells were obtained as a pellet. A portion of the pellet was freeze-dried by Freeze Dryer DC801 (Yamato Scientific Co., Ltd., Japan), and the dry weight of the cells was measured. The cell pellet was ground at $4^{\circ} \mathrm{C}$ for $30 \mathrm{~min}$ by Bug Crasher GM-01 (TAITEC Co., Japan), centrifuged at 10,000 rpm for $10 \mathrm{~min}$, and filtered through a Millipore membrane filter (pore size; 0.22 $\mu \mathrm{m}$, MERK \& Co., USA). The amounts and kinds of sugar alcohols in the filtrate were measured using HPLC with a Shimadzu Shim pack SPR-PB column (250 $\mathrm{mm} \times 7.8 \mathrm{~mm}$ ) at a column temperature of $80^{\circ} \mathrm{C}$ and a detection wavelength of $340 \mathrm{~nm}$ using RID10A detector (Shimadzu Co., Japan). Elution was performed with distilled water for HPLC (FUJIFILM Wako Pure Chemicals Co, Japan). Each sample injection volume was $20 \mu \mathrm{L}$, the flow rate was $0.5 \mathrm{~mL} /$ minute, and the detection time was within $60 \mathrm{~min}$. The ratios of the accumulated amounts of sugar alcohols $(\mathrm{mg})$ to those of dried yeast cells $(\mathrm{g})$ were calculated.

\subsection{Mutation with Ethyl Methanesulfonate and Isolation of Higher Sugar Tolerant Mutants}

Mutations were induced in the above two high-sugar-tolerance yeasts by expo- 
sure to ethyl methanesulfonate (EMS). The procedure was as follows: each strain was cultured in yeast minimum medium (D-glucose, $20 \mathrm{~g} / \mathrm{L}+\mathrm{YNB}$ without amino acids, $6.7 \mathrm{~g} / \mathrm{L}$ ) at $25^{\circ} \mathrm{C}$ for $48 \mathrm{hrs}$. One $\mathrm{mL}$ of the culture was added to 30 $\mu \mathrm{L}$ of EMS (Tokyo Chemical Industry Co. Ltd., Japan) and gently shaken at $25^{\circ} \mathrm{C}$ for $1 \mathrm{hr}$. The yeast suspension with EMS was neutralized with the same volume of $10 \%(\mathrm{w} / \mathrm{v})$ sodium thiosulfate, followed by repeated centrifugation and washing with saline. The EMS-treated yeast was cultured in $10 \mathrm{~mL}$ of YMM + sorbitol $(800 \mathrm{~g} / \mathrm{L})$ at $25^{\circ} \mathrm{C}$ for $120 \mathrm{hrs}$, spread on an agar plate of the same medium, and cultured at $25^{\circ} \mathrm{C}$ for $120 \mathrm{hrs}$. The rapidly growing colonies were identified, and the mutant of each strain with the highest sugar tolerance was isolated.

\subsection{Tests for Stress-Tolerance of the Mutants}

The mutants described above were tested for various stress tolerances. First, both the parents and the mutants were precultured in $10 \mathrm{~mL}$ of YMM + sorbitol (800 $\mathrm{g} / \mathrm{L}$ ) at $25^{\circ} \mathrm{C}$ for $120 \mathrm{hrs}$, spread on agar plates of the same medium, and cultured at $25^{\circ} \mathrm{C}$ for $120 \mathrm{hrs}$. The numbers of grown colonies of parents and mutants were compared. Second, both parents and mutants were precultured in $10 \mathrm{~mL}$ of YMM at $25^{\circ} \mathrm{C}$ for $48 \mathrm{hrs,} \mathrm{spread} \mathrm{on} \mathrm{agar} \mathrm{plates} \mathrm{of} \mathrm{YPD} \mathrm{medium,} \mathrm{and} \mathrm{cultured} \mathrm{at}$ $36^{\circ} \mathrm{C}-39^{\circ} \mathrm{C}$ for $3-5$ days to test their heat tolerance. Third, both parents and the mutants were precultured in $10 \mathrm{~mL}$ of YPD at $25^{\circ} \mathrm{C}$ for $48 \mathrm{hrs}$, and $100 \mu \mathrm{L}$ of each culture was inoculated into test tubes containing inverted Durham pipes and $10 \mathrm{~mL}$ of YPD + ethanol $(10 \%-20 \% \mathrm{v} / \mathrm{v})$. The fermentation was conducted in a test tube covered with aluminum cap for 2 weeks at $25^{\circ} \mathrm{C}$ to test their ethanol tolerance by visualizing their $\mathrm{CO}_{2}$ production.

\subsection{Ethanol Fermentation by the Yeasts in Molasses}

Molasses (ALISHAN (Japan) Co. Ltd.) was used as the substrate. We assayed sugar consumptions and ethanol productivities of both the parents and their mutants after the fermentation of molasses diluted by distilled water. Each yeast was aerobically precultured at $25^{\circ} \mathrm{C}$ for 48 hours in $10 \mathrm{~mL}$ of modified YPD medium. The growing yeast was centrifuged at $3000 \mathrm{rpm}$ for $5 \mathrm{~min}$, and its precipitate was washed with saline. The centrifugation/washing procedure was conducted three times, and the cells were obtained as a pellet. Then, $0.3 \mathrm{~g}$ of the yeast pellet was anaerobically cultured for 192 hours at $25^{\circ} \mathrm{C}$ in $10 \mathrm{~mL}$ of $25 \%$ (w/v) or 50\% (w/v) diluted molasses using the Anaero Pack System (Mitsubishi Gas Chemical Co., Japan). The sugar consumptions and ethanol productions by the yeasts were determined at specified time points with the Sucrose/D-glucose/ D-Fructose F-kit (Roche Diagonotics) and Ethanol F-kit (Roche Diagonotics) as the same method of [21].

\section{Results}

\subsection{Selection of High Sugar-Tolerant Yeasts from 6 Strains}

Figure 1 shows growth curves of the 6 strains-C. glabrata TC18, L. kluyveri 


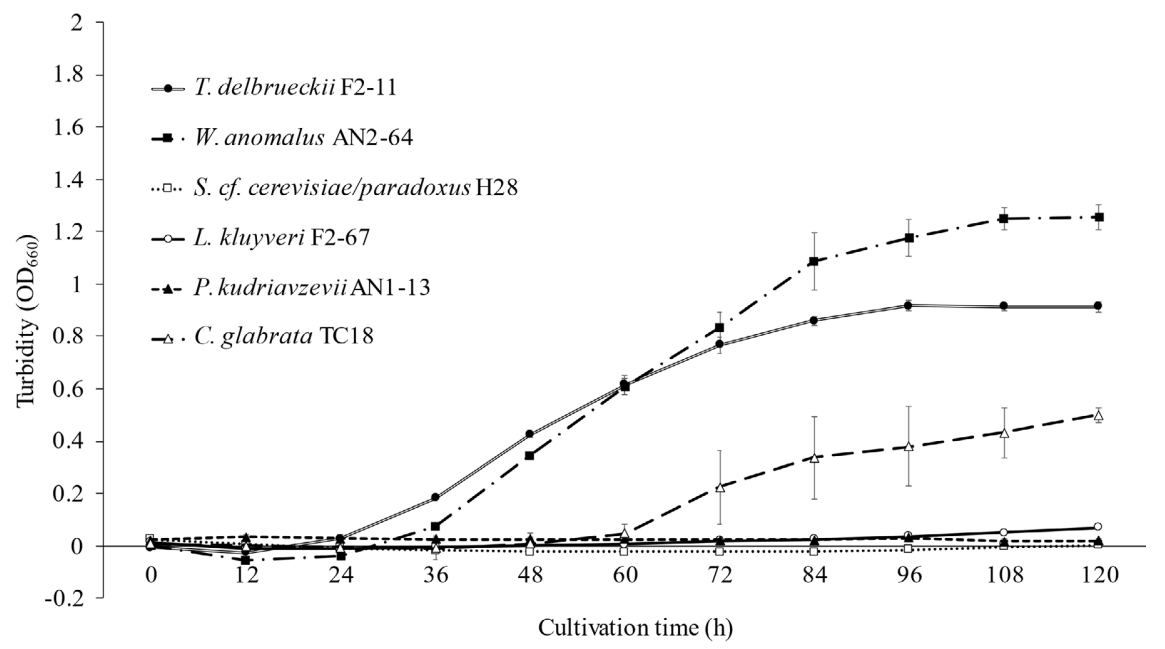

Figure 1. Growth curves of the 6 strains: Candida glabrata TC18, Lachancea kluyveri F2-67, Pichia kudriavzevii AN1-13, Saccharomyces cf. cerevisiae/paradoxus H28, Torulaspora derbrueckii F2-11, and Wicherhamomyces anomalus AN2-64. Graphs shows mean values of triplicate trials and their standard deviations (SDs).

F2-67, P. kudriavzevii AN1-13, S. cf. cerevisiae/paradoxus H28, T. derbrueckii F2-11, and $W$. anomalus AN2-64-in the YPD + sorbitol (600 g/L) medium at $25^{\circ} \mathrm{C}$ for 120 hrs. L. kluyveri F2-67, P. kudriavzevii AN1-13, and S. cf. cerevisiae/paradoxus $\mathrm{H} 28$ showed little growth and apparently did not have sugar tolerance under these conditions. C. glabrata TC18 showed low growth after $60 \mathrm{hrs}$ incubation and thus seemed to have a moderate sugar tolerance. Both T. derbrueckii F2-11 and $W$. anomalus AN2-64 showed high growth during $36-120$ hrs incubation and were selected as the candidates for high sugar tolerance.

\subsection{Amounts and Kinds of Accumulated Sugar Alcohols as Compatible Solutes in T. derbrueckii F2-11 and W. anomalus AN2-64}

Figure 2(a) shows the amounts and kinds of accumulated sugar alcohols in $T$. derbrueckii F2-11 cultures containing 20 or $400 \mathrm{~g} / \mathrm{L}$ of D-glucose, maltose, or sucrose. In all conditions, the main two kinds of sugar alcohol detected were glycerol and to a lesser extent, arabitol. The amount of glycerol at the end of the culture period increased from about 160 to 290 (mg/g cells) in the yeast as the glucose in the culture medium increased from 20 to $400 \mathrm{~g} / \mathrm{L}$. In the same manner, the final amount of glycerol significantly increased in the yeast with increasing maltose or sucrose 20 to $400 \mathrm{~g} / \mathrm{L}$ in the medium. The amounts of arabitol also increased under the same conditions; however, the major compatible solute in T. derbrueckii F2-11 was glycerol.

Figure 2(b) shows amounts and kind of accumulated sugar alcohols in $W$. anomalus AN2-64 cultures containing $20 \mathrm{~g} / \mathrm{L}$ or $400 \mathrm{~g} / \mathrm{L}$ of D-glucose, maltose, or sucrose. In all conditions, the main two kinds of sugar alcohol detected were glycerol and arabitol. The final amount of glycerol increased from 35 to 110 (mg/g cells) in the yeast as glucose in the medium increased from 20 to $400 \mathrm{~g} / \mathrm{L}$. 


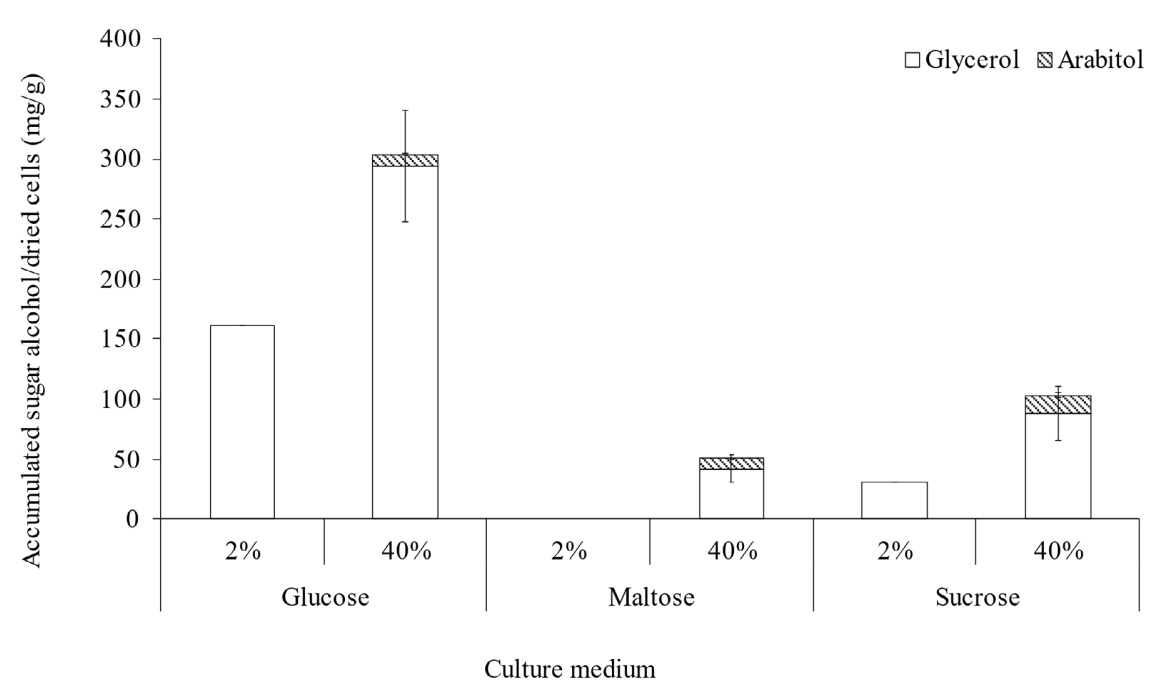

(a)

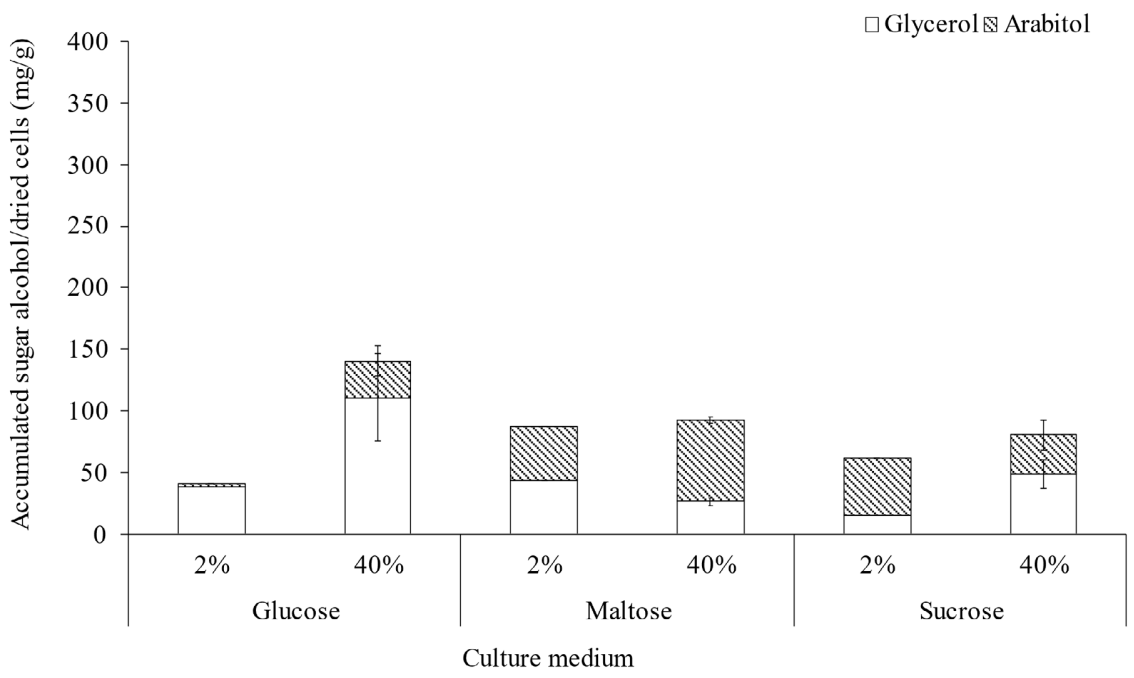

(b)

Figure 2. (a) Amounts and kinds of accumulated sugar alcohols in Torulaspora derbrueckii F2-11 in the cultivation containing $20 \mathrm{~g} / \mathrm{L}$ or $400 \mathrm{~g} / \mathrm{L}$ of D-glucose, maltose, or sucrose Bar graphs show mean values of triplicate trials and their SDs. (b) Amounts and kind of accumulated sugar alcohols in Wicherhamomyces anomalus AN2-64 in the cultivation containing $20 \mathrm{~g} / \mathrm{L}$ or $400 \mathrm{~g} / \mathrm{L}$ of D-glucose, maltose, or sucrose Bar graphs show mean values of triplicate trials and their SDs.

On the other hand, arabitol increased about 35 to $72(\mathrm{mg} / \mathrm{g}$ cells) as the maltose in the medium increased from 20 to $400 \mathrm{~g} / \mathrm{L}$. Thus, the major compatible solutes in $W$. anomalus AN2-64 were glycerol and arabitol.

\subsection{Comparison of Stress-Tolerance between the Parents and Their Mutants}

The high-sugar-tolerance mutants F2-11M and AN2-64M were isolated by selecting rapidly growing colonies from the cultures of their parents, T. derbrueckii F2-11 or $W$. anomalus AN2-64, respectively. 
Figure 3 compares the number of colonies of parent and mutant strains when grown on agar plates containing high concentrations of sugars. Both T. derbrueckii F2-11 and F2-11M were cultured on agar plates of YMM + sorbitol (800 $\mathrm{g} / \mathrm{L})$ at $25^{\circ} \mathrm{C}$ for $120 \mathrm{hrs}$. The number of F2-11M colonies was about $8.9 \times 10^{6}$ $(\mathrm{CFU} / \mathrm{mL})$ and that of F2-11 was about $2.7 \times 10^{6}$, with the former being 3.3 -fold higher than the latter. The number of AN2-64M colonies was about $8.5 \times 10^{6}$ and that of the AN2-64 was about $2.3 \times 10^{6}$, with the former being 3.7-fold higher than the latter. The sugar tolerance of the mutants was found to be higher than that of the parents.

Next, the 4 strains were grown on YPD plates at $36^{\circ} \mathrm{C}-39^{\circ} \mathrm{C}$ to test their heat tolerance. All grew well at $36^{\circ} \mathrm{C}$ while no strains grew at $39^{\circ} \mathrm{C}$ (data not shown). Figure 4 shows a photograph of the growing colonies of F2-11, the F2-11M, AN2-64, and AN2-64M at $37^{\circ} \mathrm{C}$ and $38^{\circ} \mathrm{C}$. The mutants showed higher growth than the parents at both $37^{\circ} \mathrm{C}$ and $38^{\circ} \mathrm{C}$. The heat tolerance of the mutants was found to be higher than that of the parents.

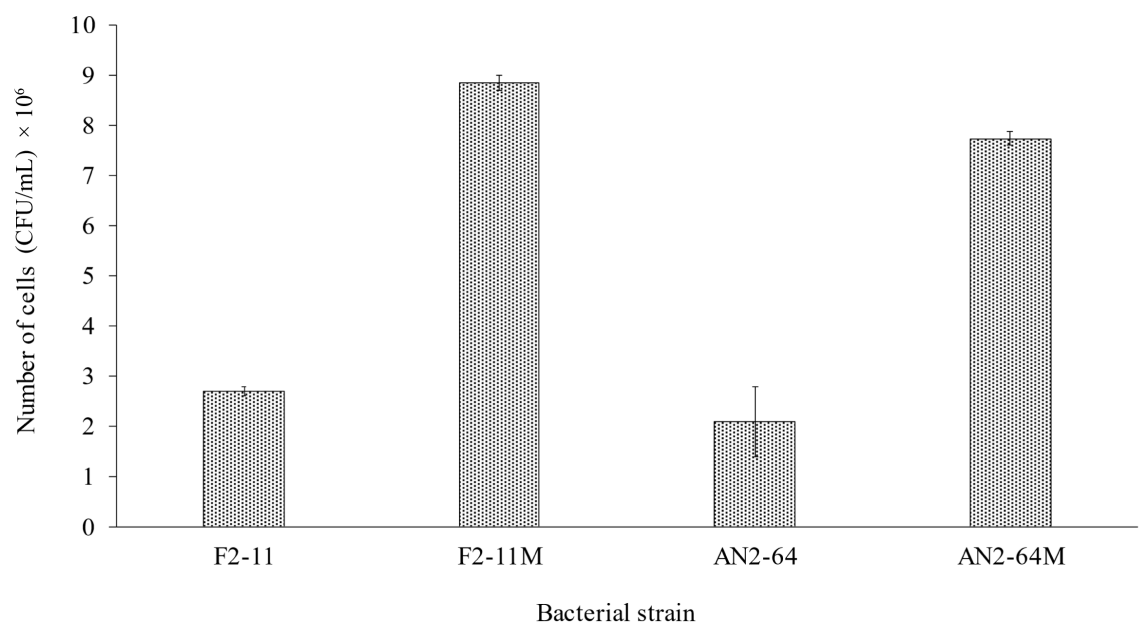

Figure 3. Comparison of number of growing colonies between the parents and their mutants on agar plates containing high concentration sugar. Bar graphs show the means of triplicate trials and their SDs.

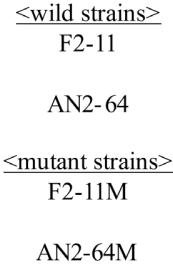

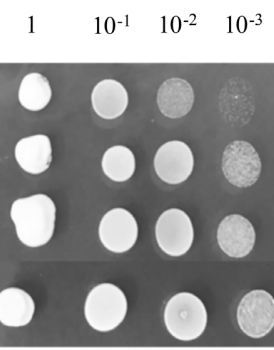

$37^{\circ} \mathrm{C}$

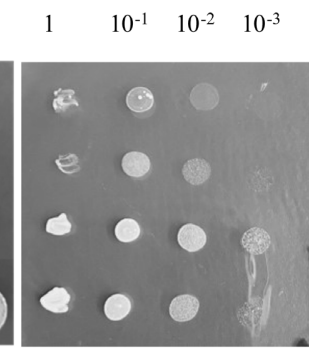

$38^{\circ} \mathrm{C}$

Figure 4. Thermotolerance of F2-11, F2-11M, AN2-64, and AN2-64M at $37^{\circ} \mathrm{C}$ and $38^{\circ} \mathrm{C}$. Each strain was precultured in $10 \mathrm{~mL}$ of $\mathrm{YMM}$ at $25^{\circ} \mathrm{C}$ for $48 \mathrm{hrs}$, and the grown cells were diluted to $10^{-3}, 10^{-2}, 10^{-1}$, or 1 by physiological saline. Two- $\mu \mathrm{L}$ portions were spread on agar plates of YPD medium and cultured at $36^{\circ} \mathrm{C}-39^{\circ} \mathrm{C}$ for $3-5$ days to testing their heat tolerance. 
Table 1 shows fermentation tests of the parents and the mutants in YPD + ethanol, 10\% - 20\% (v/v). Growth of F2-11 was high in ethanol, 10\% (v/v), moderate in $15 \%(\mathrm{v} / \mathrm{v})$, and absent in $20 \%(\mathrm{v} / \mathrm{v})$. Growth of the AN2-64 was high in ethanol $10 \%(\mathrm{v} / \mathrm{v})$ and moderate in ethanol $15 \%-20 \%(\mathrm{v} / \mathrm{v})$. On the other hand, the mutants F2-11M and AN2-64M showed high growth in ethanol, $10 \%-20 \%$ $(\mathrm{v} / \mathrm{v})$. The ethanol tolerance of the mutants was found to be higher than that of the parents.

\subsection{Sugar Assimilation and Ethanol Fermentation of the Yeasts from 25\% (v/v) Molasses}

By diluting molasses with distilled water, a $25 \%(\mathrm{v} / \mathrm{v})$ solution whose sugar components were sucrose $(104.0 \mathrm{~g} / \mathrm{L}), \mathrm{D}$-fructose $(33.4 \mathrm{~g} / \mathrm{L})$, and D-glucose $(24.8$ $\mathrm{g} / \mathrm{L}$ ) was prepared.

Figure 5(a) shows the sugar components of 25\% (v/v) molasses before and after yeast fermentation. Before fermentation, the total sugars in $25 \%(\mathrm{v} / \mathrm{v}) \mathrm{mo}-$ lasses were about $162 \mathrm{~g} / \mathrm{L}$. Residual sugars after fermentation were about $75 \mathrm{~g} / \mathrm{L}$ by F2-11, 71 g/L by F2-11M, 100 g/L by AN2-64, and 88 g/L by AN2-64M. Sugar assimilation activities of the mutants were higher those of the parents in the $25 \%$ $(\mathrm{v} / \mathrm{v})$ molasses.

Figure 5(b) shows ethanol production by yeast fermentation from $25 \%(\mathrm{v} / \mathrm{v})$ molasses. The ethanol amounts produced were $32 \mathrm{~g} / \mathrm{L}$ by F2-11 and $35 \mathrm{~g} / \mathrm{L}$ by F2-11M; $26 \mathrm{~g} / \mathrm{L}$ by AN2-64 and $33 \mathrm{~g} / \mathrm{L}$ by AN2-64M. The ethanol productions of the mutants in $25 \%(\mathrm{v} / \mathrm{v})$ molasses were also higher than those of the parents. Under these conditions, the sugar assimilation activity of each yeast was found to be highly related to its ethanol productivity.

\subsection{Ethanol Fermentation of the Yeasts from $50 \%(\mathrm{v} / \mathrm{v})$ Molasses}

By diluting molasses with distilled water, a $50 \%(\mathrm{v} / \mathrm{v})$ solution whose sugar components were sucrose $(210.2 \mathrm{~g} / \mathrm{L})$, D-fructose $(52.7 \mathrm{~g} / \mathrm{L})$, and D-glucose $(53.5$ $\mathrm{g} / \mathrm{L})$ was prepared.

Figure 6 shows the ethanol productivity of each yeast during fermentation from $50 \%(\mathrm{v} / \mathrm{v})$ molasses over the span of $192 \mathrm{hrs}$. Ethanol was produced about $77 \mathrm{~g} / \mathrm{L}$ at $48 \mathrm{hrs}$, and $94 \mathrm{~g} / \mathrm{L}$ at $120-192 \mathrm{hrs}$ by F2-11. It was produced at about $27 \mathrm{~g} / \mathrm{L}$ at $48 \mathrm{hrs}, 43 \mathrm{~g} / \mathrm{L}$ at $120 \mathrm{hrs}$ and $48 \mathrm{~g} / \mathrm{L}$ at $192 \mathrm{hrs}$ by the F2-11M. Ethanol

Table 1. Fermentation tests of the parents and the mutants. (ethanol [\% (v/v)])

\begin{tabular}{ccccc}
\hline & & 10 & 15 & 20 \\
\hline Fild strains & F2-11 & ++ & + & - \\
& AN2-64 & ++ & + & ++ \\
mutant strains & F2-11M & ++ & ++ & ++ \\
\hline
\end{tabular}

- : no fermentative, + : moderate fermentative, ++ : high fermentative 


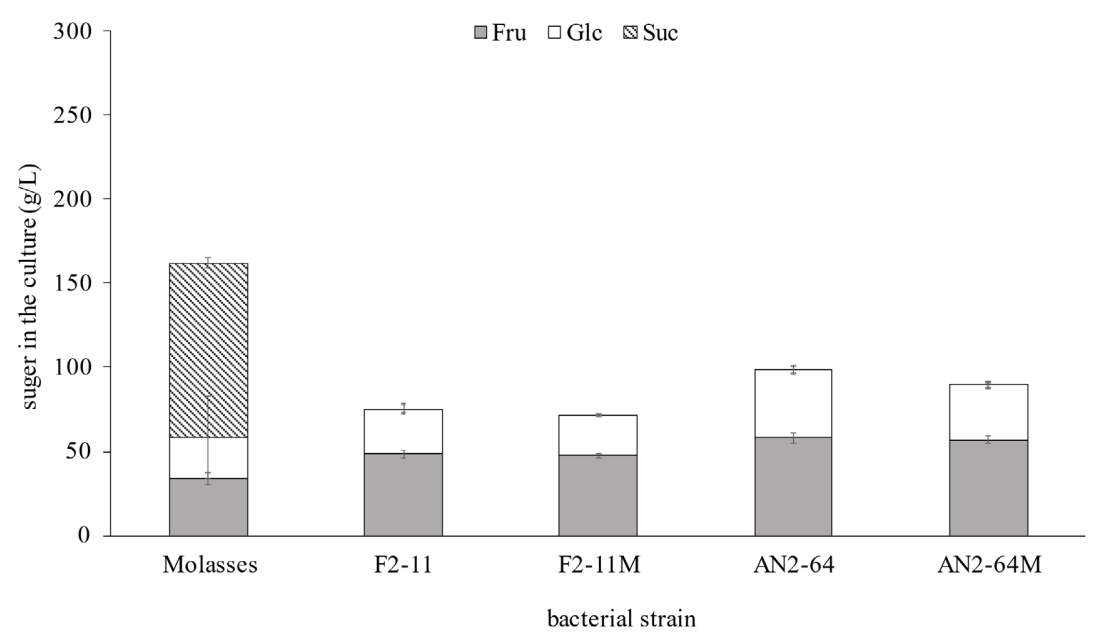

(a)

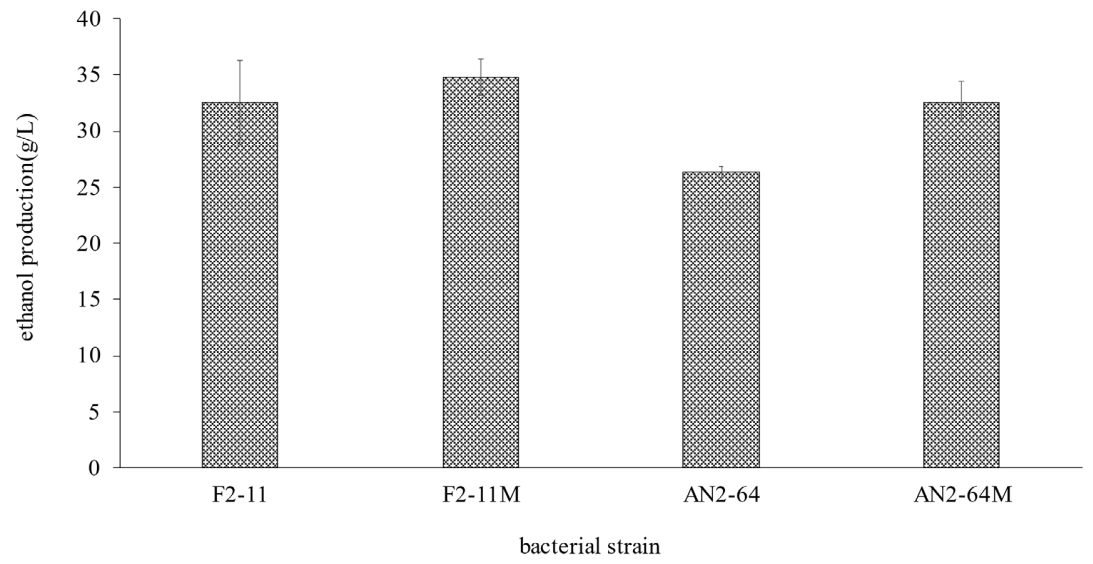

(b)

Figure 5. (a) Sugar components of $25 \%$ (v/v) molasses before and after yeast fermentation. Bar graphs show mean values of triplicate trials and their SDs. (b) Ethanol production by yeast fermentation from $25 \%(\mathrm{v} / \mathrm{v})$ molasses. Bar graphs show mean values of triplicate trials and their SDs.

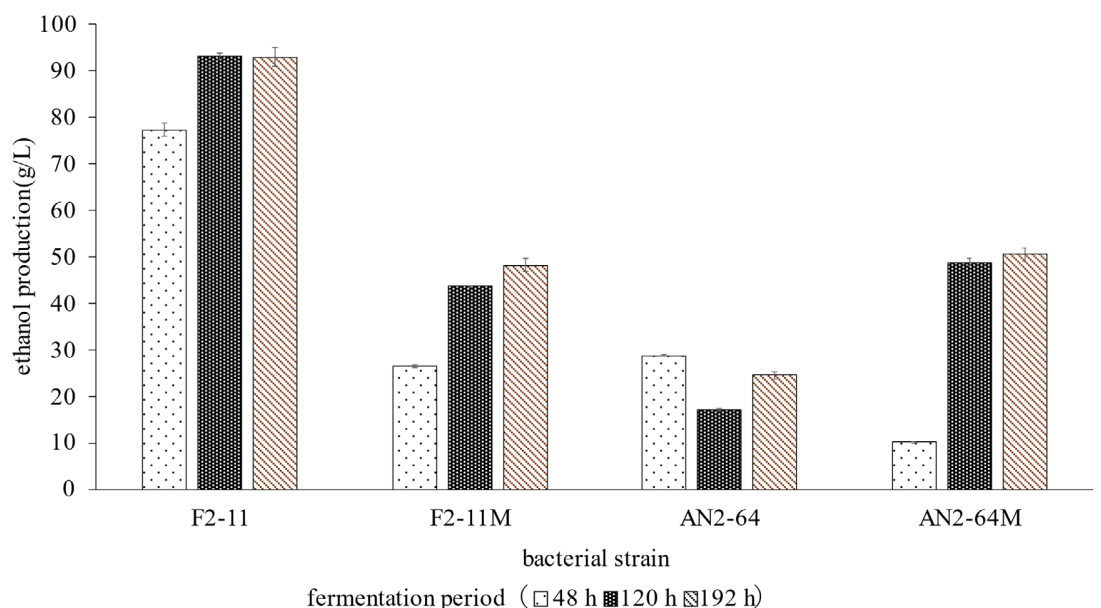

Figure 6. Ethanol productivity of each yeast during fermentation 0 - 192 hrs from $50 \%$ (v/v) molasses. Bar graphs show mean values of triplicate trials and their SDs. 
productivity of the parent (F2-11) was found to be higher than that of the mutant (F2-11M). Ethanol was also produced about $17-29 \mathrm{~g} / \mathrm{L}$ at $48-192 \mathrm{hrs}$ by AN2-64. It was produced $10 \mathrm{~g} / \mathrm{L}$ at $48 \mathrm{hrs}, 49 \mathrm{~g} / \mathrm{L}$ at $120 \mathrm{hrs}$, and $51 \mathrm{~g} / \mathrm{L}$ at 192 hrs by the AN2-64M. Ethanol productivity of the mutant (AN2-64M) was found to be higher than that of the parent (AN2-64).

\subsection{Sugar Assimilation of the Yeasts from $50 \%$ (v/v) Molasses}

To elucidate the higher ethanol productivity by F2-11, we measured the changes of residual sugars in 50\% (v/v) molasses during fermentation by F2-11 and F2-11M; results are shown in Figure 7. The total sugars in both cultures before fermentation were about $315 \mathrm{~g} / \mathrm{L}$. In F2-11, total residual sugars were about 102 $124 \mathrm{~g} / \mathrm{L}$ while residual sucrose was $0 \mathrm{~g} / \mathrm{L}$ from 48 to $192 \mathrm{hrs}$. However, in F2-11M, the total residual sugars were about $147-225 \mathrm{~g} / \mathrm{L}$ from 24 to $192 \mathrm{hrs,}$ and the residual sucrose was $14-104 \mathrm{~g} / \mathrm{L}$ from 48 to $120 \mathrm{hrs}$. Therefore, the assimilation activity of sucrose in F2-11M was found to decrease; this phenomenon was thought to have caused its decease of ethanol productivity from $50 \%$ (v/v) molasses.

\section{Discussion}

Mukherjee et al. reported an overview of non-conventional yeast species for different stress tolerance traits desirable in second-generation bioethanol production [24]. First, they identified several non-conventional osmotolerant yeast species using agar plates with increasing concentrations of glucose, fructose, and sorbitol (each $\sim 600 \mathrm{~g} / \mathrm{L}$ ). Among the list of the osmotolerant yeast species were our two key parent yeast strains, Torulaspora derbrueckii and Wicherhamomyces anomalus. Second, three different salts $(\mathrm{NaCl}, \mathrm{KCl}$, and $\mathrm{LiCl}, 2500$ - 2570 $\mathrm{mM}$ ) were used to evaluate the yeasts' halotolerance. T. derbrueckii and $W$. anomalus were also in their list of halotolerant yeast species. Third, they identified

F2-11

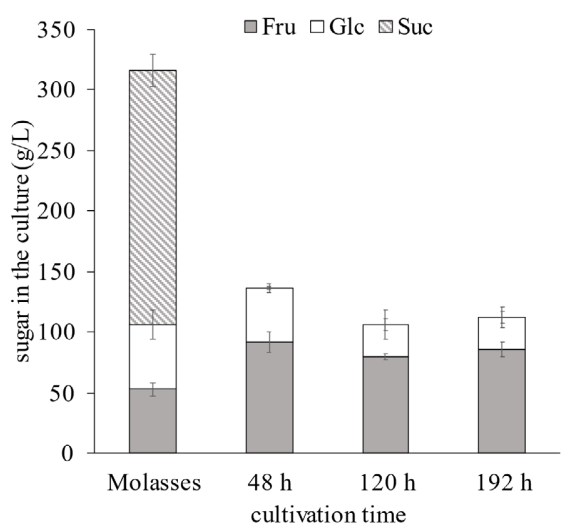

F2-11M

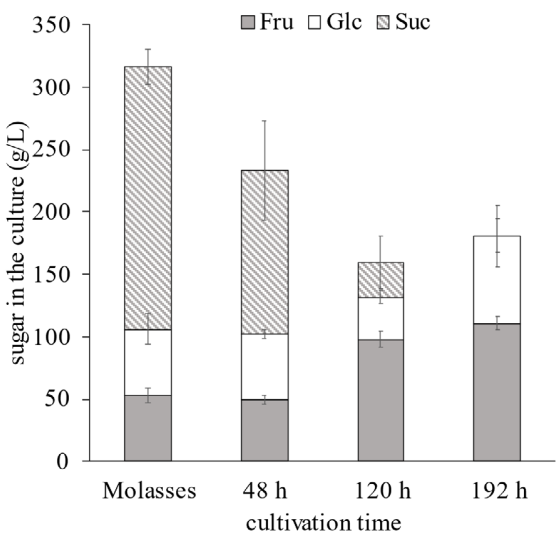

Figure 7. Change of residual sugars in $50 \%(\mathrm{v} / \mathrm{v})$ molasses during fermentation by the F2-11 or the F2-11M. Bar graphs show mean values of triplicate trials and their standard deviation SDs. 
the yeast species that grew at $41^{\circ} \mathrm{C}$; on that list of thermotolerant yeasts were Candida glabrata, Pichia kudriavzevii, Saccharomyces cerevisiae, and W. anomalus. Fourth, the "ethanol-tolerant" yeast species growing on 13\% (v/v) ethanol included $S$. cerevisiae, T. derbrueckii, and $W$. anomalus. Fifth, a growth test on 5-hydroxymethylfurfural (5-HMF, $7 \mathrm{~g} / \mathrm{L}$ ) was performed, and the 5-HMF tolerant yeast species included C. glabrata, Lachancea kluyveri, S. cerevisiae, and W. anomalus. Therefore, all 6 representative yeast species used in this study were also included on the lists of non-conventional yeast species for different stress tolerance traits [24]. T. derbrueckii and W. anomalus, our two candidates for the high-sugar-tolerance yeasts in this study, were the most frequently listed in the report [24].

Both $T$. delbrueckii and $W$. anomalus are used for wine making in some countries [25] [26], suggesting that these yeasts have tolerance against high concentrations of alcohol. W. anomalus, also known as Pichia anomala and Hansenula anomala, is frequently related to spoilage or processing of food and grain products. Its capacity for growth on a wide range of carbon sources at low $\mathrm{pH}$, under high osmotic pressure, and with little or no oxygen enables it to propagate in a wide range of environments [27]. It is a non-Saccharomyces wine yeast that contributes to the wine aroma through the production of volatile compounds. $T$. delbrueckii has also been isolated from several human bioprocesses including bread and wine industries, and is thought to be a spoilage yeast contaminating highly osmotic liquids [28].

As shown in Figure 5(a) and Figure 5(b), both sugar assimilations and ethanol productions from $25 \%(\mathrm{v} / \mathrm{v})$ molasses were higher by the mutants (F2-11M and AN2-64M) than by the parents (F2-11 and AN2-64). On the other hand, ethanol production from $50 \%(\mathrm{v} / \mathrm{v})$ molasses was higher by the parent (F2-11) than by the mutant $(\mathrm{F} 2-11 \mathrm{M})$, as shown Figure 6 . This phenomenon was explained to be caused by a decrease of sucrose assimilation activities by F2-11M, as shown in Figure 7. In general, sucrose is decomposed to D-glucose and $\mathrm{D}$-fructose in a reaction catabolized by invertase secreted from yeasts; then, the monosaccharides are taken up by the cells and assimilated. Thus, the mutation with EMS was thought to cause an increase of stress tolerance for the yeasts but simultaneously a decrease of the amount of invertase secreted from the F2-11M. There have been several studies on $S U G$ gene-defective yeast mutants; for instance, Carson et al. reported on mutants of $S$. cerevisiae that were unable to grow anaerobically on sucrose but still able to use glucose; they isolated these mutants and characterized their SUG genes mutation [29]. Therefore, it is thought to be indispensable for improving ethanol fermentation to isolate yeasts with different stress tolerance traits and without $S U G$ related gene mutations.

\section{Conclusion}

Torulaspora derbrueckii F2-11 and Wicherhamomyces anomalus AN2-64 were selected as candidates for high-sugar-tolerance yeasts, because they showed high growth in the YPD + sorbitol $(600 \mathrm{~g} / \mathrm{L})$ medium at $25^{\circ} \mathrm{C}$ for $120 \mathrm{hrs}$. The amounts 
and kinds of sugar alcohols in the strains in the cultures containing $20 \mathrm{~g} / \mathrm{L}$ or 400 $\mathrm{g} / \mathrm{L}$ of D-glucose, maltose, or sucrose were measured, and the main two sugar alcohols that accumulated with increasing sugar concentrations were glycerol and arabitol. Culture of the parents T. derbrueckii F2-11 or $W$. anomalus AN2-64 with EMS induced the mutants F2-11M or AN2-64M, respectively, which showed higher sugar, heat, and ethanol tolerances than those of the parents. Ethanol productivities of the mutants F2-11M and AN2-64 were 33 - $35(\mathrm{~g} / \mathrm{L})$ with increase of the sugar assimilation activities, while those of the parent F2-11 and AN2-64 were $26-32(\mathrm{~g} / \mathrm{L})$ in the $25 \%(\mathrm{v} / \mathrm{v})$ molasses.

\section{Conflicts of Interest}

The authors declare no conflicts of interest regarding the publication of this paper.

\section{References}

[1] Kurtzman, C.P., Fell, J.W. and Boekhout, T. (2011) The Yeasts: A Taxonomic Study. 5th Edition, Elsevier Science, New York.

[2] Álvarez-Cao, M.E., Cerdán, M.E., González-Siso, M.I. and Becerra, M. (2019) Bioconversion of Beet Molasses to Alpha-Galactosidase and Ethanol. Frontiers in $\mathrm{Mi}$ crobiology, 10, Article No. 450. https://doi.org/10.3389/fmicb.2019.00405

[3] Arshad, M., Hussain, T., Iqbal, M. and Abbas, M. (2015) Enhanced Ethanol Production at Commercial Scale from Molasses Using High Gravity Technology by Mutant S. cerevisiae. Brazilian Journal of Microbiology, 48, 403-409. https://doi.org/10.1016/j.bjm.2017.02.003

[4] Tesfaw, A. and Assefa, F. (2014) Current Trends in Bioethanol Production by Saccharomyces cerevisiae: Substrate, Inhibitor Reduction, Growth Variables, Coculture, and Immobilization. International Scholarly Research Notices, 2014, Article ID: 532852. https://doi.org/10.1155/2014/532852

[5] Azhar, S.H.M., Abdulla, R., Jambo, S.A., Marbawi, H., Gansau, J.A., Faik, A.Z.M. and Rodrigues, K.F. (2017) Yeasts in Sustainable Bioethanol Production: A Review. Biochemistry and Biophysics Reports, 10, 52-61. https://doi.org/10.1016/j.bbrep.2017.03.003

[6] Nguyen, H.P., Le, H.D. and Le, V.V.M. (2015) Effect of Ethanol Stress on Fermentation Performance of Saccharomyces cerevisiae Cells Immobilized on Nypa fruticans Leaf Sheath Pieces. Food Technology and Biotechnology, 53, 96-101. https://doi.org/10.17113/ftb.53.01.15.3617

[7] Zhang, Q., Wu, D., Lin, Y., Wang, X., Kong, H. and Tanaka, S. (2015) Substrate and Product Inhibition on Yeast Performance in Ethanol Fermentation. Energy Fuels, 29, 1019-1027. https://doi.org/10.1021/ef502349v

[8] Zaky, A.S., Tucker, G.A., Daw, Z.Y. and Du, C. (2014) Marine Yeasts Isolation and Industrial Application. FEMS Yeast Research, 14, 813-825. https://doi.org/10.1111/1567-1364.12158

[9] Greetham, D., Zaky, A.S. and Du, C. (2019) Exploring the Tolerance of Marine Yeast to Inhibitory Compounds for Improving Bioethanol Production. Sustainable Energy \& Fuels, 3, 1545-1553. https://doi.org/10.1039/C9SE00029A

[10] Ueno, R., Urano, N. and Kimura, S. (2001) Characterization of Thermotolerant, Fermentative Yeasts from Hot Spring Drainage. Fisheries Science, 67, 138-145. 
https://doi.org/10.1046/j.1444-2906.2001.00210.x

[11] Ueno, R., Urano, N. and Kimura, S. (2002) Effect of Temperature and Cell Density on the Ethanol Fermentation by a Thermotolerant, Aquatic Yeast Strain Isolated from Hot Spring Environment. Fisheries Science, 68, 571-578.

https://doi.org/10.1046/j.1444-2906.2001.00210.x

[12] Ueno, R., Hamada-Sato, N. and Urano, N. (2003) Fermentation of Molasses by Several Yeasts from Hot Spring Drain and Phylogeny of the Unique Isolate Producing Ethanol at $55^{\circ} \mathrm{C}$. Journal of the Tokyo University of Fisheries, 90, 23-30.

[13] Ogawa, G, Ishida, M., Usui, Y. and Urano, N. (2008) Ethanol Production from the Water Hyacinth Eichhornia crassipes by Yeast Isolated from Various Hydrospheres. African Journal of Microbiology Research, 2, 110-113.

[14] Takagi, T., Uchida, M., Matsushima, R., Ishida, M. and Urano, N. (2012) Efficient Bioethanol Production from Water Hyacinth Eichhornia crassipes by Both Preparation of the Saccharified Solution and Selection of Fermenting Yeasts. Fisheries Science, 78, 905-910. https://doi.org/10.1007/s12562-012-0516-2

[15] Obara, N., Ishida, M., Hamada-Sato, N. and Urano, N. (2012) Efficient Bioethanol Production from Paper Shredder Scrap by a Marine Derived Saccharomyces cerevisiae C-19. Science \& Technology Studies, 1, 49-54. https://doi.org/10.11425/sst.1.127

[16] Uchida, M., Miyoshi, T., Kaneniwa, M., Ishihara, K., Nakashimada, Y. and Urano, N. (2014) Production of $16.5 \% \mathrm{v} / \mathrm{v}$ Ethanol from Seagrass Seeds. Journal of Bioscience and Bioengineering, 118, 646-650. https://doi.org/10.1016/j.jbiosc.2014.05.017

[17] Obara, N., Okai, M., Ishida, M. and Urano, N. (2015) Bioethanol Production from Mixed Biomass (Waste of Undaria pinnatifida Processing and Paper Shredding) by Fermentation with Marine-Derived Saccharomyces cerevisiae. Fisheries Science, 81, 771-776. https://doi.org/10.1007/s12562-015-0877-4

[18] Takagi, T., Uchida, M., Matsushima, R., Komada, H., Takeda, T., Ishida, M. and Urano, N. (2015) Comparison of Ethanol Productivity among Yeast Strains Using Three Different Seaweeds. Fisheries Science, 81, 763-770. https://doi.org/10.1007/s12562-015-0875-6

[19] Okai, M., Betsuno, A., Shirao, A., Obara, N., Suzuki, K., Takei, T., Takashio, M., Ishida, M. and Urano, N. (2017) Citeromyces matritensis M37 Is a Salt Tolerant Yeast that Produces Ethanol from Salted Algae. Canadian Journal of Microbiology, 63, 20-26. https://doi.org/10.1139/cjm-2016-0259

[20] Urano, N., Shirao, A., Okai, M. and Ishida, M. (2017) High Ethanol Production by Marine-Derived Yeasts-Saccharomyces cerevisiae under Stress Pressures. Advances in Microbiology, 7, 349-357. https://doi.org/10.4236/aim.2017.75029

[21] Naito, Y., Okai, M, Ishida, M, Takasio, M. and Urano, N. (2019) Bioethanol Production from Molasses by Yeasts with Stress-Tolerance Isolated from Aquatic Environments in Japan. Advances in Microbiology, 9, 1000-1011. http://doi.org/10.4236/aim.2019.912065

[22] Atiyeh, H. and Duvnjak, Z. (2008) Production of Fructose and Ethanol from Sugar Beet Molasses Using Saccharomyces cerevisiae ATCC 36858. Biotechnology Progress, 18, 234-239. https://doi.org/10.1021/bp010164z

[23] Blomberg, A. (2006) Metabolic Surprises in Saccharomyces cerevisiae during Adaptation to Saline Conditions: Question, Some Answers and a Model. FEMS Microbiology Letters, 182, 1-8. https://doi.org/10.1111/j.1574-6968.2000.tb08864.X

[24] Mukherjee, V., Radecka, D., Aerts, G., Verstrepen, K.J., Lievents, B. and Thevelein, J.M. (2017) Phenotypic Landscape of Non-Conventional Yeast Species for Different 
Stress Tolerance Traits Desirable in Bioethanol Fermentation. Biotechnology for Biofuels, 10, Article No. 216. http://doi.org/10.1186/s13068-017-0899-5

[25] Van Breda, V., Jolly, N. and Van Wyk, J. (2012) Characterisation of Commercial and Natural Torulaspora delbrueckii Wine Yeast Strains. International Journal of Food Microbiology, 163, 80-88. https://doi.org/10.1016/j.ijfoodmicro.2013.02.011

[26] Padilla, B., Gil, J.V. and Manzanares, P. (2018) Challenges of the Non-Conventional Yeast Wickerhamomyces anomalus in Winemaking. Fermentation, 4, Article No. 68. https://doi.org/10.3390/fermentation4030068

[27] Passoth, V., Fredlund, E., Druvefors, U.A. and Schnurer, J. (2006) Biotechnology, Physiology and Genetics of the Yeast Pichia anomala. FEMS Yeast Research, 6, 3-13. https://doi.org/10.1111/j.1567-1364.2005.00004.x

[28] Albertin, W., Chasseriaud, L., Comte, G., Panfili, A., Delcamp, A., Salin, F., Marullo, P. and Bely, M. (2014) Winemaking and Bioprocesses Strongly Shaped the Genetic Diversity of the Ubiquitous Yeast Torulaspora delburueckii. PLOS ONE. 9, e94246. http://doi.org/10.1371/journal.pone.0094246

[29] Carlson, M., Osmond, B.C. and Botstein, D. (1981) Mutants of Yeast Defective in Sucrose Utilization. Genetics, 98, 25-40. https://doi.org/10.1093/genetics/98.1.25 